\title{
Influencia de tres volúmenes de contenedor en el almácigo y cultivo de coliflor
}

\author{
Influence of three plug tray cell volumes on the growth \\ of cauliflower
}

\author{
Christel Oberpaur W. ${ }^{1}$; Luis Nieto $U^{2}{ }^{2}$; Guillermo Délano I. ${ }^{3}$
}

\section{RESUMEN}

La influencia del tamaño de contenedores de almácigo se evaluó en el crecimiento y desarrollo de coliflor (Brassica oleracea L. botrytis L.) cv. Devina, desde almácigo hasta cosecha, en la Región Metropolitana en 2003. El almácigo se realizó bajo condiciones de invernadero, contemplando tres volúmenes de contenedores $\left(10,18\right.$ y $\left.43 \mathrm{~cm}^{3}\right)$, con un diseño estadístico completamente al azar, tres tratamientos y tres repeticiones. El trasplante se realizó en Curacaví $\left(33^{\circ} 25^{\prime} \mathrm{S}, 71^{\circ} 25^{\prime} \mathrm{O}\right)$, con cinco repeticiones. La evaluación estadística de los resultados fue mediante análisis de varianza (ANDEVA) y la prueba de comparación múltiple de Duncan $(\mathrm{p} \leq 0,05)$. En la etapa de almácigo las plantas contenidas en $43 \mathrm{~cm}^{3}$ alcanzaron el mayor desarrollo radicular y foliar, con un peso seco total (PS) de 377,2 mg planta ${ }^{-1}$. Las contenidas en $18 \mathrm{~cm}^{3}$ mostraron un PS de 217,2 mg planta ${ }^{-1}$, y de $152,7 \mathrm{mg} \mathrm{planta}^{-1}$ las provenientes de $10 \mathrm{~cm}^{3}$. La sobrevivencia después del trasplante no mostró diferencias entre los tratamientos. El desarrollo se mantuvo con las diferencias arrastradas desde la etapa de almácigo hasta cosecha, donde las plantas provenientes de $43 \mathrm{~cm}^{3}$ fueron más precoces, iniciando la cosecha a los 86 días después de trasplante (ddt), con un mayor peso y diámetro de pella. Se determinaron categorías de acuerdo al diámetro de pella, obteniendo en plantas provenientes de $43 \mathrm{~cm}^{3}$ un $88 \%$ de pellas con un diámetro mayor a $16 \mathrm{~cm}, 8 \%$ entre 14 y $16 \mathrm{~cm}$ y un $4 \%$ con diámetro menor a $14 \mathrm{~cm}$. En las plantas provenientes de $18 \mathrm{~cm}^{3} \mathrm{se}$ inició la cosecha a los $80 \mathrm{ddt}$ con un $66 \%, 20 \%$ y 14\%, y en plantas provenientes de $10 \mathrm{~cm}^{3}$ comenzó a los 77 ddt con un $42 \%$, $32 \%$ y $26 \%$ en cada categoría.

Palabras clave: Almácigo, trasplante, contenedor, hortaliza.

\begin{abstract}
The effect of different plug tray cell volumes on the growth and development of cauliflower (Brassica oleracea L. var. botrytis) was evaluated from plant nursery until curd harvest in the Metropolitan Region in 2003. The nursery was maintained under greenhouse conditions. Three container cell volume treatments $\left(10,18\right.$ y $\left.43 \mathrm{~cm}^{3}\right)$ were used in a completely randomized statistical design with three replicates. The transplanting was done in Curacavi $\left(33^{\circ} 25^{\prime} \mathrm{S}, 71^{\circ} 25^{\prime} \mathrm{W}\right)$ with the same statistical design and five replicates. The statistical analysis of the obtained result was performed by analysis of variance (ANOVA) and the Duncan multiple comparisons test $(P \leq 0.05)$. At the nursery stage plants grown in $43 \mathrm{~cm}^{3}$ tray cells had the highest root and foliar development, with a total dry matter weight (DM) of $377.2 \mathrm{mg} \mathrm{plant}^{-1}$. Those grown in $18 \mathrm{~cm}^{3}$ tray cells reached $217.2 \mathrm{mg}$ plant ${ }^{-1}$ and those obtained in $10 \mathrm{~cm}^{3}$ tray cells had $152.7 \mathrm{mg} \mathrm{plant}^{-1}$. The survival rate after transplant did not show statistical differences. Further development maintained the differences coming from the nursery stage until harvest; plants arising from $43 \mathrm{~cm}^{3}$ cells were more precocious, initiating harvest 77 days after transplanting (DAT) with the highest curd weight and diameter. Curd categories were established according to their diameter. Plants grown in $43 \mathrm{~cm}^{3}$ tray cells showed $88 \%$ of the curds with a diameter greater than $16 \mathrm{~cm}, 8 \%$ between 14 and $16 \mathrm{~cm} 4 \%$ under $14 \mathrm{~cm}$. Plants coming from $18 \mathrm{~cm}^{3}$ tray cells initiated harvest 80 DAT with $66 \%, 20 \%$ and 14 in these categories, respectively. Plants from $10 \mathrm{~cm}^{3}$ tray cells initiated harvest 86 DAT with $42 \%, 32 \%$ and $26 \%$ in each category.
\end{abstract}

Key words: Plant nursery, transplant, plug tray cell volume, vegetable crops, cauliflower.

\footnotetext{
1 Ing. Agr. M.Sc. Universidad Santo Tomás, Santiago, Chile. E-mail: coberpaur@ santotomas.cl

2 Ing. Agr. Universidad Santo Tomás, Santiago, Chile. E-mail: Inietou@yahoo.com

3 Ing. Agr. Universidad Santo Tomás. Santiago, Chile. E-mail: gdelano@ santotomas.cl
}

Fecha de Recepción: 13 Agosto, 2008

Fecha de Aceptación: 18 Enero, 2011 


\section{Introducción}

La coliflor (Brassica oleracea L. var. botrytis) es cultivada en Chile desde el Valle de Lluta, en Arica hasta Magallanes (Aljaro, 2000), con un total de 1369,4 ha, especialmente entre las regiones $V$ y VII, en condiciones de aire libre (Barrios, 2010). Las zonas geográficas más apropiadas corresponden a aquellas con climas típicamente costeros (Aljaro, 2000). El cultivo se inicia a través del sistema de almácigo y trasplante (Giaconi y Escaff, 1998), donde el rendimiento final depende en gran medida de la calidad de los plantines (Miskovic et al., 2009). Tradicionalmente se utiliza el almácigo para trasplantar a raíz desnuda, sin embargo el alto costo de las semillas fomenta el uso de contenedores, donde el plantín es trasplantado a raíz cubierta, es decir, con su sistema radicular intacto, lo que permite una mayor tolerancia al estrés del trasplante. Es recomendable realizar la selección del volumen del recipiente en función del momento de trasplante, de lo contrario se puede obtener una planta desbalanceada en la proporción área foliar-sistema radicular (Ne Smith y Duval, 1998; Favaro y Pilatti, 2002). El tamaño de los contenedores es generalmente una decisión económica, donde se prefieren contenedores pequeños, porque más plantas pueden crecer en un menor espacio (Singh et al., 2007). Sin embargo, los contenedores con volúmenes más grandes normalmente producen plantas más vigorosas y precoces (Kelley y Boyhan, 2003). Para brássicas se recomienda volúmenes de contenedor de $43 \mathrm{~cm}^{3}$, $23 \mathrm{~cm}^{3}$ y de $11 \mathrm{~cm}^{3}$ (Bodnar y Garton, 1996), sin embargo Miskovic et al. (2009) indican que con tamaños entre 50 y $90 \mathrm{~cm}^{3}$ se obtienen plántulas de mejor calidad. Las plantas muestran cambios fisiológicos y morfológicos en respuesta a un volumen reducido disponible para el crecimiento de las raíces, que puede afectar tanto la calidad al momento del trasplante, como su comportamiento posterior en el campo (Ne Smith y Duval, 1998). Las tasas de crecimiento de las plantas en contenedores suelen ser proporcionales al volumen de estos (Wien, 1997; Singh et al., 2007). Una reducción del volumen del contenedor aumenta generalmente las probabilidades de limitaciones a nivel radicular, entonces es necesario considerar el efecto del tiempo en que una planta permanece bajo estas condiciones (Ne Smith y Duval, 1998; Vavrina, 2002).
El momento adecuado para trasplantar depende tanto del cultivo como del volumen del contenedor. Las brássicas usualmente requieren de cinco a siete semanas desde siembra a trasplante (Vavrina, 2002).

El desarrollo de la coliflor desde trasplante a cosecha puede ser dividido en fase juvenil, inducción y desarrollo de la pella (Wien y Wurr, 1997). En la etapa juvenil la planta desarrolla el área foliar. Al cultivar la coliflor tempranamente en el verano, las plantas presentan un corto período desde plantación a inducción de pella y la iniciación de esta con una escasa cantidad de hojas. En invierno el período desde plantación a inducción de pella es más prolongado, lo que permite una mayor cantidad de hojas (Wurr y Fellows, 2000). El objetivo de esta investigación es determinar el efecto del volumen de contenedor en almaciguera sobre las plántulas y su consecuencia en el desarrollo y rendimiento de coliflor después del trasplante.

\section{Materiales y Métodos}

Durante el período junio-noviembre de 2003 se realizaron dos ensayos consecutivos, en almaciguera y posterior trasplante al aire libre. El primero, etapa de almácigo, se estableció en un invernadero calefaccionado en Talagante, Región Metropolitana, Chile. El segundo ensayo, trasplante, se realizó entre agosto y noviembre de 2003 en la comuna de Curacaví, Región Metropolitana, $\left(33^{\circ} 25^{\prime}\right.$ latitud sur, $71^{\circ} 25^{\prime}$ longitud oeste). El régimen térmico de esta zona se caracteriza por una temperatura media anual de $13,9^{\circ} \mathrm{C}$ con una máxima media del mes más cálido (enero) de $29,0{ }^{\circ} \mathrm{C}$ y una mínima media del mes más frío (julio) de $2,8^{\circ} \mathrm{C}$. El período aprovechable libre de heladas es de cinco meses, noviembre a marzo. El régimen hídrico se describe por una precipitación anual de $370 \mathrm{~mm}$, siendo el mes de julio el más lluvioso con 96,4 mm (Novoa y Villaseca, 1989).

Se utilizó semilla del cultivar híbrido Devina de coliflor. Como sustrato para los plantines se recurrió a la mezcla comercial de turba Sunshine 6, la cual contiene turba del musgo Sphagnum, macro y micronutrientes, elementos traza, cal dolomítica y agentes humidificantes, más $10 \%$ de perlita.

\section{Ensayo 1}

Para analizar la influencia del tamaño de contenedores en el crecimiento y desarrollo de coliflor 
se emplearon bandejas de poliestireno de $0,39 \mathrm{x}$ $0,64 \mathrm{~m}$, de tres volúmenes de contenedor diferentes: $10 \mathrm{~cm}^{3}, 18 \mathrm{~cm}^{3}$ y $43 \mathrm{~cm}^{3}$, correspondiendo a 432, 286 y 135 contenedores por bandeja, es decir, tres tratamientos a evaluar. Las bandejas fueron llenadas manualmente con el sustrato y sembradas mediante una línea semiautomática de siembra, con una semilla por contenedor. Posteriormente fueron trasladadas a cámara de germinación, con una humedad relativa que varía entre 90 y $100 \%$ y a una temperatura de $25^{\circ} \mathrm{C}$, por un período de 24 horas. Transcurrido este tiempo se trasladaron a invernadero, donde se ubicaron a $50 \mathrm{~cm}$ del suelo sobre plataformas de madera. La fertirrigación se realizó por un sistema de microaspersión. Como fertilizantes se aplicó Ultrasol crecimiento, en la primera etapa hasta antes de la emergencia de los cotiledones, seguido por Ultrasol crecimiento y Ultrasol 61. Desde dos hojas verdaderas en adelante se empleó una mezcla de Ultrasol crecimiento, Ultrasol 61, nitrato de potasio y nitrato de calcio. Al presentar 2 a 3 hojas verdaderas las plantas fueron sometidas a un endurecimiento por 5 a 7 días, mediante restricción de riegos, bajo sombreadero y condiciones ambientales de aire libre.

\section{Ensayo 2}

Previo al traslado de las plántulas, provenientes del ensayo 1, se realizaron labores de preparación de suelo. Los tratamientos consistieron en evaluar el efecto del tamaño de los contenedores $\left(10 \mathrm{~cm}^{3}\right.$, $18 \mathrm{~cm}^{3}$ y $43 \mathrm{~cm}^{3}$ ) empleados durante el período de almácigo, sobre el desarrollo fenológico del cultivo de coliflor al aire libre y sus características de cosecha.

Se utilizó una superficie total de $626 \mathrm{~m}^{2}$, siendo el marco de plantación de $0,75 \mathrm{~m}$ entre hileras y de $0,35 \mathrm{~m}$ sobre hilera, correspondiente a una densidad de 38.095 plantas ha $^{-1}$. El trasplante se realizó con una máquina trasplantadora Sphogia de pinzas de cuatro módulos, sobre los camellones previamente preparados.

En un principio el riego fue por aspersión, posteriormente se regó por surco. La frecuencia de riego se suministró de acuerdo a los criterios normales del agricultor. Para el control de malezas sobre la hilera se realizaron tres escardas manuales cada diez días a partir de la fecha de trasplante. Para el control de malezas entre hileras se utilizó un cultivador de tres módulos el que tenía adaptado un abonador. En la fertilización fueron aplicados en total $115 \mathrm{~kg} \mathrm{ha}^{-1}$ de N, $92 \mathrm{~kg} \mathrm{ha}^{-1}$ de $_{2} \mathrm{O}_{5}$ y $96 \mathrm{~kg} \mathrm{ha}^{-1}$ de $\mathrm{K}_{2} \mathrm{O}$, parcializado en cuatro oportunidades: la primera antes del trasplante, y luego a los 10, 23 y 40 días después.

\section{Diseño y análisis estadísticos}

Para el ensayo de almácigos se utilizó un diseño estadístico completamente al azar con tres tratamientos $\left(10,18\right.$ y $\left.43 \mathrm{~cm}^{3}\right)$ y tres repeticiones. La unidad experimental fue una bandeja de poliestireno. En el ensayo de trasplante a cosecha se utilizó un diseño estadístico completamente al azar, con tres tratamientos y cinco repeticiones. $\mathrm{La}$ unidad experimental correspondió a una parcela de 2,25 $\mathrm{m}$ de ancho por $18,55 \mathrm{~m}$ de largo, la cual consistió en tres hileras, donde sólo se evaluó la hilera central quedando las laterales como hileras bordes. En ambos ensayos la evaluación estadística de los resultados obtenidos y la posible existencia de diferencias entre tratamientos fue determinada mediante análisis de varianza (ANDEVA). En caso de haber diferencias significativas entre tratamientos se realizó la prueba de comparación múltiple de Duncan ( $\mathrm{p} \leq 0,05)$. Los valores obtenidos como porcentajes fueron transformados según Bliss antes de someterlos al análisis estadístico.

\section{Evaluaciones del ensayo 1}

Se realizaron cinco evaluaciones en la etapa de almácigos; la primera 10 días después de la siembra (dds) y las siguientes se efectuaron cada 7 días. Se seleccionaron tres plantas centrales, al azar, por cada unidad experimental, dejando nueve plantas bordes. Se evaluó peso seco de raíces, tallos, cotiledones y hojas; cantidad de hojas y altura de la planta.

\section{Evaluaciones del ensayo 2}

A los 10 días después del trasplante (ddt) se evaluó sobrevivencia de las plantas en terreno. Las evaluaciones de desarrollo y crecimiento se realizaron cada 20 días hasta cosecha. De la hilera central, de las unidades experimentales, se evaluaron dos plantas al azar con la condición de que la planta estuviera en competencia perfecta. Las plantas se llevaron a un horno de secado a $60^{\circ} \mathrm{C}$ hasta peso constante. Se evaluaron los siguientes parámetros: altura de planta, altura de tallo, cantidad de hojas y peso seco 
de hojas. Se dejó una franja central de 10 plantas sin intervenir destinada a evaluación de rendimiento final. La cosecha se realizó cuando la pella se encontraba con sus hojas envolventes expandidas y con color completamente blanco. Los parámetros evaluados fueron precocidad de cosecha; diámetro y peso de la pella. La precocidad de cosecha se consideró cuando un $10 \%$ de la población presentó el criterio de cosecha indicado.

\section{Resultados y Discusión}

\section{Ensayo 1: etapa de almácigo}

Peso seco de raíz: Hubo diferencias significativas entre los tamaños de contenedor sobre peso seco de raíz a partir de los 24 días después de siembra (dds) presentando, en promedio, las plántulas provenientes de contendores de $43 \mathrm{~cm}^{3}$ de volumen un $294 \%$ más de peso seco que las del contenedor de $18 \mathrm{~cm}^{3}$, y un $385 \%$ más de peso seco que las provenientes del contenedor de $10 \mathrm{~cm}^{3}$ (Cuadro 1).

Estas diferencias significativas $(\mathrm{p} \leq 0,05)$ se conservaron hasta el final de esta etapa. Vavrina (2001) sugiere que plantas provenientes de celdas más grandes presentan una reducción general del estrés, favoreciendo un mayor crecimiento radical y un mejor desarrollo de la planta, lo que coincide con los resultados de Cebula (2009). Mugnai et al. (2000) indican que la restricción de las raíces afecta la cantidad de hojas, reduciendo su número y desarrollo.

Peso seco de tallo: Al igual que la medición de altura de planta, el peso seco de tallo no presentó inicialmente diferencias significativas entre tratamientos (Cuadro 1). Solo después de que se presentó una diferencia significativa en peso seco de raíces pudo manifestarse una diferencia significativa de peso seco de tallos a favor de los contenedores de mayor volumen. Taiz y Zeiger (2006) señalan que en algunos casos la producción de etileno, bajo condiciones de estrés, por efecto de auxinas puede llevar a una inhibición del crecimiento del tallo.

Peso seco de cotiledones: No existen diferencias significativas entre los volúmenes de contenedor en la primera evaluación. En las mediciones a los 17 dds y 24 dds las plantas contenidas en el volumen de $10 \mathrm{~cm}^{3}$ presentaron cotiledones más pequeños, reflejándose esto en el peso seco. Las plantas contenidas en los volúmenes de 43 y $18 \mathrm{~cm}^{3}$ no manifestaron diferencias significativas entre ellas (Cuadro 1). En las evaluaciones siguientes ( 31 y $38 \mathrm{dds}$ ) se aprecia diferencia significativa entre todos los tratamientos, mostrando un mayor peso de cotiledones las plantas

Cuadro 1. Efecto del volumen del contenedor sobre el peso seco $\left(\mathrm{mg} \mathrm{planta}^{-1}\right)$ en coliflor cv. Devina, etapa de almácigos, de raíces, tallo, cotiledones y hojas

\begin{tabular}{|c|c|c|c|c|c|}
\hline Contenedor $\left(\mathrm{cm}^{3}\right)$ & $10 \mathrm{dds}$ & $17 \mathrm{dds}$ & $24 \mathrm{dds}$ & $31 \mathrm{dds}$ & $38 \mathrm{dds}$ \\
\hline \multicolumn{6}{|l|}{ Raíces } \\
\hline 10 & $0,53 \mathrm{a}$ & $1,80 \mathrm{a}$ & $6,5 \mathrm{a}$ & $23,6 \mathrm{a}$ & 25,9 a \\
\hline 18 & $0,63 \mathrm{a}$ & $1,73 \mathrm{a}$ & $8,0 \mathrm{~b}$ & $33,1 \mathrm{~b}$ & $40,6 \mathrm{~b}$ \\
\hline 43 & $0,46 \mathrm{a}$ & $1,50 \mathrm{a}$ & $31,5 \mathrm{c}$ & $50,0 \mathrm{c}$ & $66,5 \mathrm{c}$ \\
\hline \multicolumn{6}{|l|}{ Tallo } \\
\hline 10 & $0,60 \mathrm{a}$ & $1,33 \mathrm{a}$ & $3,43 \mathrm{a}$ & $10,93 \mathrm{a}$ & $17,26 \mathrm{a}$ \\
\hline 18 & $0,76 \mathrm{a}$ & $1,30 \mathrm{a}$ & $3,60 \mathrm{a}$ & $14,30 \mathrm{~b}$ & $18,10 \mathrm{~b}$ \\
\hline 43 & $0,66 \mathrm{a}$ & $1,23 \mathrm{a}$ & $4,23 \mathrm{a}$ & $22,32 \mathrm{c}$ & $29,20 \mathrm{c}$ \\
\hline \multicolumn{6}{|l|}{ Cotiledones } \\
\hline 10 & $0,00813 \mathrm{a}$ & $0,0107 \mathrm{a}$ & $0,0133 \mathrm{a}$ & $0,0380 \mathrm{a}$ & $0,0327 \mathrm{a}$ \\
\hline 18 & $0,00796 \mathrm{a}$ & $0,0130 \mathrm{~b}$ & $0,0205 \mathrm{~b}$ & $0,0558 \mathrm{~b}$ & $0,0456 \mathrm{~b}$ \\
\hline 43 & $0,00706 \mathrm{a}$ & $0,0128 \mathrm{~b}$ & $0,0210 \mathrm{~b}$ & $0,0748 \mathrm{c}$ & $0,0640 \mathrm{c}$ \\
\hline \multicolumn{6}{|l|}{ Hojas } \\
\hline 10 & & & & $0,0354 \mathrm{a}$ & $0,0941 \mathrm{a}$ \\
\hline 18 & & & & $0,0595 \mathrm{~b}$ & $0,1310 \mathrm{~b}$ \\
\hline 43 & & & & $0,0926 \mathrm{c}$ & $0,2467 \mathrm{c}$ \\
\hline
\end{tabular}

dds: Días después de la siembra.

Promedios unidos por letras iguales en la columna indican ausencia de diferencias estadísticamente significativas entre tratamientos, según Duncan $(\mathrm{p} \leq 0,05)$. 
desarrolladas en el volumen de $43 \mathrm{~cm}^{3}$, seguidas por las de 18 y $10 \mathrm{~cm}^{3}$, respectivamente. En la última evaluación el peso de todos los tratamientos disminuyó debido a la abscisión de algunos cotiledones, pero se mantuvieron las diferencias significativas entre tratamientos. Este mayor crecimiento podría ser respuesta a un mayor contenido de citoquininas (Taiz y Zeiger, 2006).

Peso seco foliar y cantidad de hojas desplegadas en etapa de almácigo: Respecto al peso seco de las hojas (Cuadro 1), a los 31 dds se evaluó la cantidad de hojas $\geq 1 \mathrm{~cm}$, existiendo diferencias significativas entre todos los volúmenes de contenedores. Las de mayor desarrollo foliar fueron las plantas contenidas en el volumen de $43 \mathrm{~cm}^{3}$ seguido por las de $18 \mathrm{~cm}^{3}$ y $10 \mathrm{~cm}^{3}$, respectivamente. Mayores tamaños de raíz y tallo, expresados como peso seco, permiten mayor desarrollo de área foliar y esto a su vez crecimientos futuros mayores. En cuanto al número de hojas, estas se desplegaron a los 26 dds en las plantas contenidas en volúmenes de $43 \mathrm{~cm}^{3}$, mostrando siempre un mayor número y desarrollo en comparación a los demás volúmenes de contenedor. En la última evaluación, a los $38 \mathrm{dds}$, el contenedor de $10 \mathrm{~cm}^{3}$ presentaba, en promedio, 2,44 hojas por planta; el de $18 \mathrm{~cm}^{3} 3,0$ hojas por planta y el de $43 \mathrm{~cm}^{3} 3,44$ hojas por planta. Al realizar evaluación estadística se aprecia que existen diferencias significativas entre los tratamientos $(\mathrm{p} \leq 0,05)$.

Influencia del volumen de los contenedores en altura durante etapa de almácigos: En relación a la altura de la planta (Cuadro 2) a los 10 dds no existe una diferencia significativa entre los volúmenes de 10 y $18 \mathrm{~cm}^{3}$, pero sí entre estos dos y el de $43 \mathrm{~cm}^{3}$, que es significativamente menor. Esto se debió a una emergencia anticipada de las plántulas del contenedor de menor volumen, debido probablemente a diferencias en la temperatura alcanzada por el sustrato. Sin embargo, en la tercera evaluación, a los 24 dds, las alturas se equipararon entre los tratamientos no existiendo diferencia significativa entre ellos. A los 31 dds hubo un crecimiento explosivo, evidenciando una diferencia significativa $(\mathrm{p} \leq 0,05)$ entre todos los volúmenes de contenedor, obteniendo mayor altura las plantas contenidas en los contenedores de $43 \mathrm{~cm}^{3}$. En la última evaluación de almácigo la diferencia entre los tratamientos se mantiene, pero disminuye la velocidad de crecimiento debido a que las plántulas fueron sometidas a endurecimiento.

Los resultados obtenidos coinciden con los obtenidos por Romano et al. (2003) quienes indican que el volumen del contenedor modifica significativamente el peso seco total, cantidad de hojas y área foliar de solanáceas (tomate, berenjena y pimiento) en almaciguera. Singh et al. (2007) explican que probablemente un mayor volumen de contenedor produce plántulas más vigorosas por una mayor disponibilidad de agua y nutrientes. Sin embargo, Xu y Kafkafi (2001) especifican que un aumento en la aplicación de agua y nutrientes no es suficiente para compensar la influencia de una restricción extrema de las raíces dada por una reducción del volumen de contenedor desde 33 $\mathrm{cm}^{3}$ a $9 \mathrm{~cm}^{3}$ en pimiento. Según Wien (1997) la reducción del crecimiento de plántulas, cuando son sometidas a una restricción física en su sistema radicular, no puede ser explicada por un solo factor. Malladi y Burns (2007) asocian la incidencia de diferentes reguladores de crecimiento que comunican información generadas por situaciones de estrés entre los distintos tejidos. La interacción entre auxinas y citoquininas, estas últimas producidas por las raíces, tiene un efecto sobre el crecimiento aéreo, que puede manifestarse a través de una pérdida de la dominancia apical o un menor crecimiento.

Cuadro 2. Efecto del volumen del contenedor sobre la altura $(\mathrm{cm})$ de la planta en coliflor cv. Devina, etapa de almácigo

\begin{tabular}{clllll}
\hline Contenedor $\left(\mathrm{cm}^{3}\right)$ & $10 \mathrm{dds}$ & $17 \mathrm{dds}$ & $24 \mathrm{dds}$ & $31 \mathrm{dds}$ & $38 \mathrm{dds}$ \\
\hline 10 & $1,30 \mathrm{~b}$ & $2,31 \mathrm{a} \mathrm{b}$ & $4,83 \mathrm{a}$ & $6,73 \mathrm{a}$ & $10,08 \mathrm{a}$ \\
18 & $1,23 \mathrm{~b}$ & $2,15 \mathrm{a}$ & $4,70 \mathrm{a}$ & $8,46 \mathrm{~b}$ & $11,21 \mathrm{~b}$ \\
43 & $0,95 \mathrm{a}$ & $2,56 \mathrm{~b}$ & $5,10 \mathrm{a}$ & $10,55 \mathrm{c}$ & $13,28 \mathrm{c}$ \\
\hline
\end{tabular}

dds: Días después de la siembra.

Promedios unidos por letras iguales en la columna indican ausencia de diferencias estadísticamente significativas entre tratamientos, según Duncan $(\mathrm{p} \leq 0,05)$. 


\section{Ensayo 2: desarrollo del cultivo al aire libre}

Los diferentes volúmenes de contenedor no afectan la tasa de sobrevivencia, ya que los tres tratamientos no presentan diferencias significativas $(\mathrm{p} \leq 0,05)$ y en promedio su valor es de un $98,86 \%$.

Influencia del volumen de los contenedores en altura de la planta de coliflor: La diferencia de altura se arrastró desde la etapa de almácigo y se mantuvo durante la etapa de desarrollo de cultivo, tal como lo muestra el Cuadro 3. La altura de la planta siempre fue mayor en las plantas desarrolladas en contenedores de $43 \mathrm{~cm}^{3}$ manteniendo diferencias significativas entre los tratamientos, siendo las plantas provenientes de contenedores de $10 \mathrm{~cm}^{3}$ las más pequeñas.

Influencia del volumen de los contenedores en cantidad de hojas desarrolladas: Las diferencias significativas en la cantidad de hojas totales (Cuadro 4) se mantuvieron durante toda esta etapa. Las plantas provenientes de contenedores de $43 \mathrm{~cm}^{3}$ siempre tuvieron un mayor desarrollo, reflejado en una mayor cantidad de hojas. Las procedentes de volúmenes de $10 \mathrm{~cm}^{3}$ fueron menos desarrolladas presentando una menor cantidad de hojas. Estos resultados coinciden con los obtenidos por Godoy y Cardoso (2005) donde por un menor volumen de contenedor en almaciguera la cantidad de hojas por planta al momento de cosecha también es menor.

\section{Inicio de cosecha}

En las plantas provenientes de almácigos contenidas en $43 \mathrm{~cm}^{3}$ la cosecha se inició a los 86 días después del trasplante (ddt), en las plantas contenidas en $18 \mathrm{~cm}^{3}$ comenzó a los 80 ddt y en las del tratamiento $10 \mathrm{~cm}^{3}$ a los $77 \mathrm{ddt}$ (Cuadro 5). Así, desde el punto de vista productivo las plantas provenientes de almácigos contenidos en $10 \mathrm{~cm}^{3}$ fueron las más precoces en todo su desarrollo. Esta diferencia de precocidad podría ser consecuencia de la etapa de almácigo.

Influencia del volumen de los contenedores en peso y diámetro de la pella: El peso y diámetro de la pella de coliflor (Cuadro 5), a igual fecha, fue mayor en las plantas provenientes de contenedores de $43 \mathrm{~cm}^{3}$, seguidas por las pellas de plantas de contenedores de $18 \mathrm{~cm}^{3}$ y las más pequeñas las provenientes de contenedores de $10 \mathrm{~cm}^{3}$. Siempre hubo diferencias

Cuadro 3. Efecto del volumen del contenedor en la altura $(\mathrm{cm})$ de plantas de coliflor cv. Devina después del trasplante

\begin{tabular}{cccccc}
\hline Contenedor $\left(\mathrm{cm}^{3}\right)$ & $11 \mathrm{ddt}$ & $20 \mathrm{ddt}$ & $40 \mathrm{ddt}$ & $60 \mathrm{ddt}$ & $75 \mathrm{ddt}$ \\
\hline 10 & $13 \mathrm{a}$ & $20,0 \mathrm{a}$ & $30,0 \mathrm{a}$ & $41,4 \mathrm{a}$ & $58,9 \mathrm{a}$ \\
18 & $14 \mathrm{a}$ & $24,4 \mathrm{~b}$ & $35,0 \mathrm{~b}$ & $47,8 \mathrm{~b}$ & $64,0 \mathrm{~b}$ \\
43 & $17 \mathrm{~b}$ & $30,7 \mathrm{c}$ & $42,0 \mathrm{c}$ & $54,6 \mathrm{c}$ & $73,5 \mathrm{c}$ \\
\hline
\end{tabular}

ddt: Días después de trasplante.

Promedios unidos por letras iguales en la columna indican ausencia de diferencias estadísticamente significativas entre tratamientos, según Duncan $(\mathrm{p} \leq 0,05)$.

Cuadro 4. Efecto del volumen del contenedor sobre la cantidad de hojas en coliflor cv. Devina durante su desarrollo fenológico

\begin{tabular}{cccccc}
\hline Contenedor $\left(\mathrm{cm}^{3}\right)$ & $11 \mathrm{ddt}$ & $20 \mathrm{ddt}$ & $40 \mathrm{ddt}$ & $60 \mathrm{ddt}$ & $75 \mathrm{ddt}$ \\
\hline 10 & $4,6 \mathrm{a}$ & $6,6 \mathrm{a}$ & $8,1 \mathrm{a}$ & $11,8 \mathrm{a}$ & $14,5 \mathrm{a}$ \\
18 & $5,6 \mathrm{~b}$ & $7,4 \mathrm{~b}$ & $9,0 \mathrm{~b}$ & $13,1 \mathrm{~b}$ & $16,0 \mathrm{~b}$ \\
43 & $6,7 \mathrm{c}$ & $9,5 \mathrm{c}$ & $10,2 \mathrm{c}$ & $14,0 \mathrm{c}$ & $18,7 \mathrm{c}$ \\
\hline
\end{tabular}

ddt: Días después de trasplante.

Promedios unidos por letras iguales en la columna indican ausencia de diferencias estadísticamente significativas entre tratamientos, según Duncan $(\mathrm{p} \leq 0,05)$. 
Cuadro 5. Efecto del volumen del contenedor en el peso y diámetro de pella de coliflor cv. Devina

\begin{tabular}{cccc}
\hline Contenedor almácigo $\left(\mathrm{cm}^{3}\right)$ & Inicio de cosecha (días) ddt & Peso $\left(\mathrm{kg} \mathrm{planta}^{-1}\right)$ & Diámetro $(\mathrm{cm})$ \\
\hline 10 & 77 & $1,0 \mathrm{a}$ & $15,5 \mathrm{a}$ \\
18 & 80 & $1,2 \mathrm{~b}$ & $16,7 \mathrm{~b}$ \\
43 & 86 & $1,4 \mathrm{c}$ & $18,4 \mathrm{c}$ \\
\hline
\end{tabular}

ddt: Días después de trasplante

Promedios unidos por letras iguales en la columna indican ausencia de diferencias estadísticamente significativas entre tratamientos, según Duncan $(\mathrm{p} \leq 0,05)$.

Cuadro 6. Efecto del volumen del contenedor en categorías de tamaño de coliflor cv. Devina a cosecha expresado como \% del total

\begin{tabular}{|c|c|c|c|}
\hline Contenedor almácigo $\left(\mathrm{cm}^{3}\right)$ & $\begin{array}{l}\text { Categoría } 1^{\circ} \\
>16 \mathrm{~cm}(\%)\end{array}$ & $\begin{array}{c}\text { Categoría } 2^{\circ} \\
14-15,9 \mathrm{~cm}(\%)\end{array}$ & $\begin{array}{c}\text { Categoría } 3^{\circ} \\
12-13,9 \mathrm{~cm}(\%)\end{array}$ \\
\hline 10 & 42 & 32 & 26 \\
\hline 18 & 66 & 20 & 14 \\
\hline 43 & 88 & 8 & 4 \\
\hline
\end{tabular}

significativas entre los tratamientos. Aquí se puede ratificar que las plantas con mayor desarrollo y cantidad de hojas alcanzaron pellas con mayor diámetro y peso, lo que también coincide con los resultados obtenidos por Godoy y Cardoso (2005) y Cebula (2009).

A su vez en la distribución de las pellas cosechadas según categorías de diámetros (Cuadro 6) los tratamientos difieren notablemente, observándose que a medida que aumenta el volumen de contenedor del cual provienen las plantas en almaciguera hay prevalencia de pellas con diámetros mayores.

Es necesario realizar un análisis detallado de los requerimientos de mercado en cuanto a tamaño y peso de las pellas con su valoración económica. Solo así es posible establecer la conveniencia de utilizar contenedores de mayor o menor volumen, y por ende de mayor o menor costo por plántula, en relación al retorno esperado en cosecha según destino de la producción (mercado fresco tradicional, supermercado o agroindustria).

En conclusión la disminución del tamaño de contenedores de almácigo desde $43 \mathrm{~cm}^{3}$ a $18 \mathrm{~cm}^{3}$ y $10 \mathrm{~cm}^{3}$ afecta negativamente el desarrollo radicular y aéreo de plántulas de coliflor. La sobrevivencia del almácigo postrasplante no es influenciada por el tamaño de contenedores en que se desarrollaron las plántulas. La reducción del tamaño de contenedores en un almácigo de coliflor favorece la precocidad, disminuye el tamaño de las pellas cosechadas e influye en las categorías de calidad según diámetro. Para decidir el tamaño de los contenedores es necesario conocer el objetivo de la producción. Según los antecedentes obtenidos en esta investigación si se desean obtener coliflores de mayor calibre y peso se debieran escoger los contenedores más grandes. Si los objetivos comerciales son obtener pellas más pequeñas, es una buena opción seleccionar los contenedores más pequeños.

\section{Literatura Citada}

Aljaro, A

2000 Cultivo de brásicas, repollo, coliflor, brócoli, repollito de Bruselas. Tierra Adentro (34) 12-14.

Barrios, B.

2010 Características generales de coliflor y brócoli. Odepa. Consultado 18 enero 2011. Disponible en http://www.odepa. gob.cl/odepaweb/publicaciones/doc/2402.pdf
Bodnar, J.; Garton, R

1996 Growing Vegetable Transplants in Plug Trays. Ministry of Agriculture, Food and Rural Affairs. Ontario. Factsheets 96-023.

Cebula, S.

2009 The effect of pot size and transplant age on the yield and quality of white, green and romensco cauliflower curds. Vegetable Crops Research Bulletin (70) 101-110. 
Favaro, J; Pilatti, R.

2002 El cultivo del tomate en invernaderos. Universidad Nacional del Litoral Facultad de Ciencias Agrarias Cultivos Intensivos.

Giaconi, V.; Escaff, M.

1998 Cultivo de hortalizas. Editorial Universitaria. Santiago, CL. 336 p.

Godoy, M.C.; Cardoso, A.I.

2005 Cauliflower production depending on age of seedling and cell size of the trays. Hortic. Bras. 23 (3) 837-840.

Kelley, T.; Boyhan, G.E.

2003 Containers and media. In: Commercial production of vegetable transplants. University of Georgia, College of Agricultural and Environmental Sciences. Bulletin $\mathrm{N}^{\circ} 1144$.

Krarup, C.; Grazidi, P.

1998 Agroindustria de congelados, requerimientos y variedades de coliflor. Agroeconómico Fundación Chile 43 (2): 36-40.

Malladi, A.; Burns, J.

2007 Communication by Plant Growth Regulators in Roots and Shoots of Horticultural Crops. HortScience 42(5): 1113-1117.

Miskovic, A.; Ilin, Z.; Markoviz, V.; Cervenski, J. 2009 Effect of Substrate Type and Volume of Container Cell on Quality of Brassicas Seedlings. Proc. IS on Prot. Cult. Mild Winter Climate. Acta Hort. (ISHS) 807: 603-606.

Mugnai, S.; Vernieri, P.; Tognoni, F. 2000 Container Volume Effects on Morphology and Physiology of Tomato Seedlings. Acta Hort. (ISHS) 516: 499-505.

Ne Smith, D.S; Duval, J.R.

1998 The Effect of Container Size. HortTechnology. OctoberDecember 8 (4) 495-498.

Novoa, R.; Villaseca, S.

1989 Mapa Agroclimático de Chile. Editorial Idea. Santiago, CL. 221 p.

Romano, D.; Paratore, A.; Rosi, A.L.

2003 Plant density and container cell volume on solanaceous seedling growth. VI International Symposium on Protected
Cultivation in Mild Winter Climate: Product and Process Innovation. Acta Hort. (ISHS) 614: 247-253.

Singh, B.; Yadav H.L.; Sirohi, N.

2007 Effect of Plastic Plug-Tray Cell Size and Shape on Quality of Soilless Media Grown Tomato Seedlings. Proc. Int. Conf. and Exhibition on Soilless Curture. Acta Hort. (ISHS) 742: 57-60.

Taiz, L.; Zeiger, E.

2006 Plant Physiology. $4^{\text {th }}$ Edition. Sianuer Associates, Inc. Publishers. Sunderland, Massachusetts. 764 p.

Vavrina, C.S.

2001 Bigger is Actually Better: A Study of Transplant Container Cell Size (en línea). University of Florida. IFAS Extension. HS817. Consultado 13 agosto 2008. Disponible en: http://imok.ufl.edu/veghot/trans/isbigger.htm.

Vavrina, C.S.

2002 An Introduction to the Production of Containerized Vegetable Transplants. University of Florida. Institute of Food and Agricultural Science. Fact Sheet HS849. $16 \mathrm{p}$.

Wien, H.C.

1997 Transplanting. In: Wien, H.C. 1997. The Physiology of Vegetable Crops. Cabi Publishing. Reprinted in 2002. $662 \mathrm{p}$.

Wien, H.C.; Wurr, D.C.E.

1997 Cauliflower, Broccoli, Cabbage and Brussel Sprouts. In: Wien, H.C. 1997. The Physiology of Vegetable Crops. Cabi Publishing. Reprinted in 2002. 662 p.

Wurr, D.C.E.; Fellow, J.R.

2000 Temperature influences on the plant development of different maturity types of cauliflower. Proc. III Int. Symp. on Brassicas. Acta Hort. (ISHS) 539: 69-74.

Xu, G.; Kafkafi, U.

2001 Nutrient supply and container size effects on flowering, fruiting, assimilate allocation, and water relations of sweet pepper. World Congress on Soilless Culture: Agriculture in the Comming Millennium. Acta Hort. (ISHS) 554: 113-120. 